\title{
Psychometric Properties of Behavioral Checklist for Coping with Stress in Patients with Mood Disorders
}

\author{
Hyun Ju Lim¹, Eunsoo Moon ${ }^{1,2} \bowtie$, Hwagyu Suh¹, Sun Kyeong Yang1', Je Min Park¹,2, Byung Dae Lee ${ }^{1,2}$, \\ Young Min Lee ${ }^{1,2}$, Hee Jeong Jeong', Soo Yeon Kim¹, Kang Yoon Lee', and Min Yoon ${ }^{3}$ \\ ${ }^{1}$ Department of Psychiatry and Medical Research Institute, Pusan National University Hospital, Busan, Republic of Korea \\ ${ }^{2}$ Department of Psychiatry, Pusan National University School of Medicine, Yangsan, Republic of Korea \\ ${ }^{3}$ Department of Applied Mathematics, Pukyung National University, Busan, Republic of Korea
}

\begin{abstract}
Objective Even though the importance of stress-coping, there is no reliable and valid scale to measure the stress-coping behavior yet. The purpose of this study is to explore the psychometric properties of Behavioral Checklist for Coping with Stress (BCCS).

Methods A total of 458 subjects including healthy subjects and patients with bipolar or depressive disorders were analyzed. The reliability and validity of BCCS were examined by Chronbach's alpha and exploratory factor analysis using Principal Component Analysis. In order to evaluate criterion-related validity, the Pearson's correlation analyses between factors of BCCS and relevant scales were performed.

Results BCCS showed good Chronobach's alpha (0.695-0.833) and had acceptable validity. Factor 1 and factor 4 of BCCS were negatively correlated with depression, anxiety and positivity correlated with task and problem-solving, avoidance, tension-releasing copings in common. Factor 2 and 3 were positively correlated with impulsivity, emotionality, avoidance, behavioral and verbal aggression and tension-releasing copings in common. Different from factor 2, factor 3 was positively correlated with depression, anxiety and anger-suppression.
\end{abstract}

Conclusion The results of this study suggest that this BCCS might be a reliable and valid scale for measuring stress-coping behaviors. This scale could facilitate research to investigate clinical implications related to behavioral stress-coping.

Psychiatry Investig 2021;18(2):147-156

Key Words Stress, Coping, Behavior, Scale, Mood disorder.

\section{INTRODUCTION}

Stressful events could be one of the important factors affecting the onset and prognosis of psychiatric disorders. ${ }^{1,2}$ Especially, there were significant relationships between stressful life events and mood disorders. Stressful life events in childhood play an important role in the onset of major depressive disorder. ${ }^{3}$ An experience of childhood emotional abuse is associated with higher risk of depressive symptoms when confronted with stressful situations. ${ }^{4}$ In bipolar disorder, stressful life events can have negative influences on the onset and course.

Received: July 4, 2020 Revised: October 28, 2020

Accepted: December 5, 2020

$\triangle$ Correspondence: Eunsoo Moon, MD, PhD

Department of Psychiatry, Pusan National University Hospital, Pusan National University School of Medicine, 179 Gudeok-ro, Seo-gu, Busan 49241, Republic of Korea

Tel: +82-51-240-7303, Fax: +82-51-248-3648, E-mail: esmun@hanmail.net

(c) This is an Open Access article distributed under the terms of the Creative Commons Attribution Non-Commercial License (https://creativecommons.org/licenses/by$\mathrm{nc} / 4.0$ ) which permits unrestricted non-commercial use, distribution, and reproduction in any medium, provided the original work is properly cited.
Stressful life events related to social rhythm disruption were associated with the onset of manic episode in bipolar disorder. ${ }^{5}$ Negative life events also predicted increase of depressive symptoms and delayed recovery from mood episodes in patients with bipolar disorder., ${ }^{67}$

In order to minimize the negative consequences of stressful life events, it is crucial to cope with stress efficiently. Nevertheless, patients with mood disorders often fail to properly cope with stressful situations. Compared to healthy people, patients with depression are likely to use maladaptive coping, such as avoidance and denial, and have difficulties in finding positive meanings from stressful events. ${ }^{8}$ Bipolar patients are more likely to use emotion-focused coping related to negative consequences than healthy controls. ${ }^{9}$ A recent study implies the differential effects of coping strategies between bipolar disorder and depressive disorder. ${ }^{10}$ This study reported that patients with depressive disorder tend to use less task and avoidant coping than patients with bipolar disorders.

Previous studies on stress-coping strategies mostly focused 
on cognitive strategies and emotional stress responses. ${ }^{11,12}$ As a matter of fact, it is well known that these factors were meaningfully related to mood symptoms and prognosis in mood disorders. ${ }^{13,14}$ Cognitive strategies such as problem-solving coping or task-oriented coping were associated with cognitive control to properly solve stressful situations through the functions of the frontal lobe. ${ }^{15}$ Meanwhile, emotional coping such as self-blaming or emotional outburst might reflect the overactivity of the emotional neural circuit by the stress responses caused by inappropriate coping. ${ }^{16}$ These cognitiveemotional approaches were mainly addressed. ${ }^{17}$

In contrast, the behavioral aspect on stress-coping had less attention than cognitive-emotional strategy until now. In fact, many people frequently take their own stress-coping behaviors to relieve stress responses. ${ }^{18}$ For instance, someone can use behaviors to seek relaxation, such as reading a book, taking a shower or meditating. Otherwise, people would try to pursue the pleasure-seeking behaviors to compensate for the discomfort caused by stressful situations, such as gambling, reckless driving or smoking. Besides, someone can have a reaction towards stressful situations, such as crying and bingeeating. Like these, people can show a number of behaviors in stressful situations. Some behaviors could be associated with adaptive coping to reduce stress responses properly. In contrast, several behaviors improperly cope with stress and can lead to negative consequences.

Given that the popularity of stress-coping behaviors as coping strategies, it could be clinically useful to measure stresscoping behaviors. Since stress-coping behaviors are explicitly revealed, it is easy to recognize and modulate their own stresscoping strategies. If people tend to use maladaptive coping behaviors, an intervention to change maladaptive behaviors to adaptive behaviors can be applied. For these reasons, measuring and analyzing stress-coping behaviors can be important in the evaluation and management of people suffering from stressful situations. However, there is lack of scale to efficiently measure the stress-coping behaviors among scales that measure stress-coping strategies. ${ }^{11,12}$ Though several stress-coping scales were used in patients with mood disorders, stress-coping behaviors were assessed by only a few items in scales. ${ }^{11,12,13,19}$ Some obstacles, such as diversity of stress-coping behaviors and difference in individual intentions to use stress-coping behaviors, may discourage developing stress-coping behavior scales. A previous study implies that these behaviors could be classified into several groups, such as personal activity, pleasure-seeking activity, compulsive activity and social activity. ${ }^{18}$ The purpose of this study is to examine psychometric properties of the behavioral checklist for coping with stress (BCCS) used in the previous study in order to explore the potentiality for developing a scale to measure stress-coping behaviors in patients with mood disorders.

\section{METHODS}

\section{Study design}

This study cross-sectionally examined the reliability and validity of BCCS in patients with bipolar or depressive disorder and healthy subjects.

\section{Subjects}

A total of 458 subjects including 161 patients with bipolar or depressive disorders and 297 healthy subjects were analyzed. The patients with bipolar or depressive disorders were recruited from the subjects who visited the Mood disorder clinic in the department of psychiatry at Pusan National University Hospital between January 2012 and January 2019. Inclusion criteria was as follows: 1) patients with diagnosed as bipolar disorders or depressive disorders according to the Diagnostic and Statistical Manual of Mental disorder 4th Edition (DSM-IV-TR). The exclusion criteria were as follow: 1) patients who had serious medical diseases, 2) patients with organic mental disorders or mental retardation, and 3) illiterate people. Among 97 patients with bipolar disorders, 32 subjects were diagnosed with bipolar I disorder (33.0\%), 24 subjects with bipolar II disorder (24.7\%) and 41 subjects with bipolar disorder not otherwise specified (42.3\%). In 64 patients had depressive disorders, 39 subjects had major depressive disorder (60.9\%), 5 subjects had dysthymic disorder (7.8\%) and 20 subjects had depressive disorder not otherwise specified (31.3\%). The healthy subjects were recruited from the people encountered in public places, such as transportation stations, malls, hospitals, places of business and educational institutions. The inclusion criteria were as follow: 1) subjects at age of 18-65 years old, 2) no distressing problems requiring psychiatric treatment. The exclusion criteria were as follow: 1) people with any history of psychiatric diagnosis and treatment, 2) persons who had serious medical diseases, 3) individuals with organic mental disorders or mental retardation, and 4) illiterate people. The purpose of the study was explained to each participant, and their written informed consent was obtained. Sociodemographic and clinical characteristics of participants in this study are shown in Table 1 . This study was approved by the Pusan National University Hospital Institutional Review Board (H-1804-024-066).

\section{Assessments}

\section{Behavioral checklist for coping with stress (BCCS)}

The BCCS was used to evaluate stress-coping behaviors. ${ }^{18}$ After stress-coping behaviors were interviewed in patients 
Table 1. Sociodemographic and clinical characteristics of patients with bipolar or depressive disorder and healthy subjects

\begin{tabular}{|c|c|c|c|c|c|c|}
\hline & $\begin{array}{l}\text { Patients with } \\
\text { bipolar disorder } \\
(\mathrm{N}=97)\end{array}$ & $\begin{array}{c}\text { Patients with } \\
\text { depressive disorder } \\
(\mathrm{N}=64)\end{array}$ & $\begin{array}{l}\text { Healthy subjects } \\
\qquad(\mathrm{N}=297)\end{array}$ & F or $\chi^{2}$ & $\mathrm{p}$ & $\begin{array}{c}\text { Post hoc test } \\
\text { (Scheffe) }\end{array}$ \\
\hline Female* & $57(58.8)$ & $32(50.0)$ & $151(50.8)$ & 2.011 & 0.366 & \\
\hline Age & $31.5( \pm 10.5)$ & $34.6( \pm 14.1)$ & $33.3( \pm 9.3)$ & 1.840 & 0.160 & \\
\hline Education & $14.0( \pm 2.0)$ & $13.6( \pm 2.4)$ & $15.71( \pm 2.3)$ & 36.738 & $<0.001$ & $\mathrm{BD}, \mathrm{DD}<\mathrm{HC}$ \\
\hline Job & & & & 73.644 & $<0.001$ & \\
\hline No & $52(53.6)$ & $34(53.1)$ & $56(18.9)$ & & & \\
\hline Part-time & $7(7.2)$ & $3(4.7)$ & $10(3.4)$ & & & \\
\hline Full-time & $36(37.1)$ & $26(40.6)$ & $231(77.8)$ & & & \\
\hline Others & $2(2.1)$ & $1(1.6)$ & $0(0.0)$ & & & \\
\hline Marital status & & & & 37.664 & $<0.001$ & \\
\hline Unmarried & $63(64.9)$ & $36(56.3)$ & $157(52.9)$ & & & \\
\hline Married & $21(21.6)$ & $22(34.4)$ & $136(45.8)$ & & & \\
\hline Divorced or bereaved & $13(13.5)$ & $6(9.3)$ & $4(1.3)$ & & & \\
\hline \multicolumn{7}{|l|}{ Psychiatric diagnosis } \\
\hline Bipolar I disorder & $32(33.0)$ & & & & & \\
\hline Bipolar II disorder & $24(24.7)$ & & & & & \\
\hline Bipolar disorder NOS & $41(42.3)$ & & & & & \\
\hline Major depressive disorder & & $39(60.9)$ & & & & \\
\hline Dysthymic disorder & & $5(7.8)$ & & & & \\
\hline Depressive disorder NOS & & $20(31.3)$ & & & & \\
\hline BDI & $23.9( \pm 14.4)$ & $28.0( \pm 12.5)$ & $6.5( \pm 6.1)$ & 214.174 & $<0.001$ & $\mathrm{DD}>\mathrm{BD}>\mathrm{HC}$ \\
\hline STAI-S & $54.4( \pm 16.2)$ & $57.6( \pm 11.4)$ & $38.5( \pm 9.8)$ & 114.547 & $<0.001$ & $\mathrm{BD}, \mathrm{DD}>\mathrm{HC}$ \\
\hline STAI-T & $55.6( \pm 15.3)$ & $58.1( \pm 10.5)$ & $39.4( \pm 9.3)$ & 128.404 & $<0.001$ & $\mathrm{BD}, \mathrm{DD}>\mathrm{HC}$ \\
\hline BIS & $69.0( \pm 13.2)$ & $68.5( \pm 11.5)$ & $62.0( \pm 9.1)$ & 22.288 & $<0.001$ & $\mathrm{BD}, \mathrm{DD}>\mathrm{HC}$ \\
\hline
\end{tabular}

Values represent N (\%), or mean ( \pm SD). *Fisher's exact test. NOS: not otherwise specified, BDI: Beck Depression Inventory, STAI-S: State-Trait Anxiety Inventory-State, STAI-T: State-Trait Anxiety Inventory-Trait, BIS: Barratt Impulsivity Scale

with mood disorders, a 53-item behavioral checklist for coping with stress was collected. Even though the previous study showed the possibility of developing the BCCS as a scale for measuring stress-coping behaviors, several items in it showed problems of low factor loading and highly correlated with other factors simultaneously. In this study, after removing items with low factor loading and high factor loading on more than two items, 39-item behavioral checklist was finally used. The main question of the BCCS asked "How often do you use the following behaviors to cope with stress?" Each behavioral item of the BCCS to above question was responded in a 5-point Likert scale (0 to 4 score).

\section{Beck Depression Inventory II (BDI-II)}

BDI is a self-reported scale developed by Beck in order to evaluate the severity of depressive symptoms. ${ }^{20}$ The BDI is composed of 21-item and measure emotional, cognitive, motivational and physiological aspects of depression. The valida- tion study of the Korean version of BDI-II in this study showed good reliability and validity. ${ }^{21}$ According to this study, a depressive state was defined as a cut-off score of 18 .

\section{State-Trait Anxiety Inventory (STAI)}

The STAI is a self-reported scale developed by Spielberger to measure anxiety symptoms in clinical populations as well as general populations. ${ }^{22}$ The STAI is consist of 20 -item of state anxiety and 20 -item of trait anxiety. State anxiety means an anxiety in response of specific situation, trait anxiety means an innate anxiety trait. After measuring the state anxiety, the trait anxiety is evaluated subsequently. In this study, the Korean version of STAI which was translated by Kim was used. ${ }^{23}$

\section{Barratt impulsivity scale (BIS)}

The BIS is a 30-item self-rated scale developed by Barratt to measure impulsivity. ${ }^{24}$ The BIS consists of three factors, cognitive impulsiveness, motor activity impulsiveness and non- 
planning impulsiveness. The cognitive impulsiveness is related to rapid decision, motor activity impulsiveness means to act something without thought and non-planning impulsiveness refers to lack of plan for the future. This study used the Korean version which was translated by Lee. ${ }^{25}$

\section{Coping inventory for stressful situation (CISS)}

The CISS is a 48-item self-report scale developed by Endler and Parker to measure coping strategy in stressful situations. ${ }^{26}$ The CISS is composed of three factors task-oriented coping, emotion-oriented coping and avoidance-oriented coping. Task-oriented coping describes intentional task-oriented efforts or attempts to change the situation to solve the problem. Emotion-oriented coping refers to a self-oriented emotional reaction to reduce stress, self-preoccupation and fantasizing. Avoidance-oriented coping is related to the activities and cognitive changes to avoid stressful situation. The Korean version of CISS used in this study had acceptable reliability and validity in a previous study with Korean adolescent samples and patients with mood disorders. ${ }^{19,27}$

\section{Anger Coping Scale (ACS)}

The ACS is a 44-item self-report inventory developed by Koh to measure coping strategy in situations to provoke anger. $^{28}$ The ACS is composed of five factors, behavioral aggression, verbal aggression, problem-solving, tension releasing and anger suppression. Behavioral and verbal aggression refer to venting his/her anger by beating, having physical quarrel, cursing or having verbal quarrel. Problem-solving coping is an effort to look for a proper solution in the anger situation. Tension-releasing coping means finding a way to alleviate inner anger feeling. Anger suppression is avoiding anger outburst and holding anger feeling. In this study, the Korean version of ACS developed by Koh was used. ${ }^{28}$

\section{Statistics}

Categorical variables were compared by chi-square test, and continuous variables were compared by independent $\mathrm{t}$ test. The clinical characteristics among more than three groups were analyzed by analysis of variance (ANOVA) and post hoc test with Scheffe. The reliability of this checklist was evaluated by Chronbach's alpha representing internal consistency. Exploratory Factor Analysis was performed to evaluate the construct validity of behavioral items for measuring stresscoping behaviors. Principal Component Analysis was used to extract factors. Numbers of factors were made from the decisions by four factors for the consideration of scree plot, the size of eigenvalues and the number of factors in the previous study. We chose items greater than 0.35 as a cutoff for the factor loading. In order to evaluate criterion-related validity, the Pear- son's correlation analysis between the factors of the BCCS and relevant scales, such as BDI, STAI, BIS, CISS, and ACS, was performed. Furthermore, the factors of the BCCS were compared among three groups that consists of patients with bipolar disorders, patients with depressive disorders and healthy subjects by ANOVA and post hoc test with Scheffe. The Statistical analyses were performed using the Statistical Package for Social Sciences version 23.0 (IBM Corp., Armonk, NY, USA). A two-tailed p-value $<0.05$ was considered as a statistical significance.

\section{RESULTS}

\section{Sociodemographic and clinical characteristics of the sample}

Sociodemographic and clinical characteristics of patients with bipolar or depressive disorders and healthy subjects in this study are shown in Table 1 . Mean ages of the subjects in this study were 31.48 years $( \pm 10.537)$ in patients with bipolar disorders, 34.55 years $( \pm 14.097)$ in patients with depressive disorders and 33.26 years $( \pm 9.296)$ in healthy subjects. There were no significant differences in age and sex among three groups. In contrast, sociodemographic such as education, job and marital status showed significant differences among three groups (education $\mathrm{p}<0.001$; job $\mathrm{p}<0.001$; marital status $\mathrm{p}<$ 0.001 ). There were significant differences in clinical variables, such as BDI, STAI-S, STAI-T and BIS among three groups (BDI $\mathrm{p}<0.001$; STAI-S $\mathrm{p}<0.001$; STAI-T $\mathrm{p}<0.001 ;$ BIS $\mathrm{p}<0.001)$.

\section{The reliability of behavioral checklist for coping with stress}

The values of Chronbach's alpha in factors are shown in Table 2 . The values were ranged from 0.695 to 0.833 and within acceptable or excellent levels.

\section{The construct validity of behavioral checklist for coping with stress}

According to exploratory factor analysis, structural validity was evaluated. Four factors explained 17.1\%, 9.7\%, 7.1\% and $5.2 \%$ of the variance in total scores and accounted for $39.1 \%$. Items in factor 1 (personal activity) showed a factor loading higher than 0.310 ('drinking coffee'). Items in factor 2 (pleasureseeking activity) showed a factor loading higher than 0.379 ('stealing'). Items in factor 3 (compulsive activity) a showed factor loading higher than 0.258 ('sleep'). The item of 'saying nasty things' had high factor loadings on factor $3(0.373)$ and 4 (-0.351) simultaneously. Items in factor 4 (social activity) showed a factor loading higher than 0.378 ('social club'). The item of 'talking something over' had high factor loadings on factor $3(0.414)$ and $4(-0.564)$ simultaneously. The item of 
HJ Lim et al.

Table 2. Factor analysis of stress-coping behaviors of patients with bipolar or depressive disorders $(\mathrm{N}=161)$ and healthy subjects $(\mathrm{N}=297)$

\begin{tabular}{|c|c|c|c|c|}
\hline \multirow{2}{*}{ Behavioral checklist } & Factor 1 & Factor 2 & Factor 3 & Factor 4 \\
\hline & Personal activity & Pleasure-seeking activity & Compulsive activity & Social activity \\
\hline Reading a book & $0.716^{*}$ & -0.158 & -0.027 & 0.101 \\
\hline Writing & $0.613^{*}$ & -0.135 & 0.251 & 0.114 \\
\hline Drinking tea & $0.613^{*}$ & -0.090 & 0.017 & -0.161 \\
\hline Bathing shower & $0.612^{*}$ & 0.086 & -0.031 & -0.106 \\
\hline Taking a walk & $0.611^{*}$ & -0.084 & -0.145 & -0.087 \\
\hline Meditation & $0.597^{*}$ & -0.016 & -0.158 & 0.200 \\
\hline Exercise & $0.596^{*}$ & 0.174 & -0.204 & -0.044 \\
\hline Doing housework & $0.535^{*}$ & -0.126 & 0.177 & -0.090 \\
\hline Sauna & $0.503^{*}$ & 0.232 & -0.103 & -0.185 \\
\hline Massage & $0.475^{*}$ & 0.228 & -0.002 & -0.132 \\
\hline Dancing & $0.439^{*}$ & 0.324 & -0.007 & -0.138 \\
\hline Yoga & $0.387^{*}$ & 0.045 & 0.095 & 0.024 \\
\hline Wandering about & $0.350^{*}$ & 0.075 & 0.117 & -0.329 \\
\hline Drinking coffee & 0.310 & 0.038 & 0.143 & -0.114 \\
\hline Gambling & 0.102 & $0.654^{*}$ & 0.050 & 0.096 \\
\hline Smoking & -0.222 & $0.630^{*}$ & -0.173 & -0.042 \\
\hline Reckless driving & 0.056 & $0.613^{*}$ & 0.028 & -0.019 \\
\hline Extramarital affair & 0.070 & $0.590^{*}$ & 0.159 & 0.132 \\
\hline Fast driving & 0.097 & $0.575^{*}$ & 0.013 & -0.085 \\
\hline Having sex & 0.212 & $0.559^{*}$ & -0.139 & -0.125 \\
\hline Masturbation & -0.067 & $0.527^{*}$ & 0.035 & 0.042 \\
\hline Drinking alcohol & -0.078 & $0.479^{*}$ & -0.129 & -0.291 \\
\hline Computer game & -0.117 & $0.433^{*}$ & 0.019 & -0.046 \\
\hline Using drug/illegal substance & 0.189 & $0.389^{*}$ & 0.129 & 0.271 \\
\hline Stealing & 0.152 & $0.379^{*}$ & 0.181 & 0.291 \\
\hline Crying & -0.034 & -0.229 & $0.687^{*}$ & -0.119 \\
\hline Binge eating & -0.039 & 0.128 & $0.644^{*}$ & -0.178 \\
\hline Overeating & -0.012 & 0.087 & $0.602^{*}$ & -0.102 \\
\hline Being alone & 0.167 & -0.135 & $0.539^{*}$ & 0.254 \\
\hline Throwing things & -0.156 & 0.340 & $0.529^{*}$ & 0.043 \\
\hline Hitting & -0.076 & 0.338 & $0.467^{*}$ & 0.180 \\
\hline Saying nasty things & -0.191 & 0.268 & $0.373^{* \dagger}$ & $-0.351^{\dagger}$ \\
\hline Sleeping & 0.221 & -0.044 & 0.258 & -0.125 \\
\hline Socializing with friends & 0.170 & 0.073 & -0.094 & $-0.711^{*}$ \\
\hline Chatting & 0.141 & -0.143 & 0.245 & $-0.701^{*}$ \\
\hline Making phone calls & 0.208 & -0.049 & 0.166 & $-0.681^{*}$ \\
\hline Talking something over & 0.041 & -0.058 & $0.414^{\dagger}$ & $-0.564^{* \dagger}$ \\
\hline Journey & $0.396^{\dagger}$ & 0.046 & -0.091 & $-0.428^{* \dagger}$ \\
\hline Social_club & 0.331 & 0.199 & -0.072 & $-0.378^{*}$ \\
\hline Chronbach's alpha & 0.833 & 0.724 & 0.695 & 0.813 \\
\hline Eigen value & 6.666 & 3.776 & 2.76 & 2.012 \\
\hline Explained proportion (\%) & 17.093 & 9.681 & 7.076 & 5.160 \\
\hline
\end{tabular}

*indicate items greater than 0.40 of factor loading, tindicate items greater than 0.35 of factor loading simultaneously. 
'journey' also had high factor loadings on factor 1 (0.396) and $4(-0.428)$ simultaneously.

\section{The criterion-related validity of behavioral checklist for coping with stress}

The results of Pearson's correlation between BCCS and other scales are shown in Table 3. Factor 1 (personal activity) was negatively correlated with BDI, STAI-T, STAI-S and BIS (BDI $\mathrm{p}<0.001$; STAI-S $\mathrm{p}<0.001$; STAI-T $\mathrm{p}<0.001$; BIS $\mathrm{p}<0.001$ ). Factor 2 (pleasure-seeking activity) was positively correlated with BIS ( $\mathrm{p}<0.001)$. Factor 3 (compulsive activity) was positively correlated with BDI, STAI-T, STAI-S and BIS (BDI $\mathrm{p}<$ 0.001 ; STAI-S $p<0.001$; STAI-T $p<0.001$; BIS $p<0.001)$. Factor 4 (social activity) was negatively correlated with BDI, STAT-S and STAI-T (BDI $p<0.001$; STAI-S $\mathrm{p}<0.001$; STAI-T $\mathrm{p}<0.001$ ).

In a correlation analysis with the CISS, factor 1 (personal activity) was positively correlated with task-oriented $(\mathrm{p}<0.001)$ and avoidance-oriented copings of the CISS $(\mathrm{p}<0.001)$ and negatively correlated with emotion-oriented coping $(\mathrm{p}=0.020)$. Factor 2 (pleasure seeking activity) was positively correlated with emotion-oriented $(\mathrm{p}=0.044)$ and avoidance-oriented coping of the CISS $(\mathrm{p}=0.001)$. Factor 3 (compulsive activity) was negatively correlated with task-oriented coping $(\mathrm{p}=0.010)$ and positively correlated with avoidance-oriented coping of the CISS ( $\mathrm{p}<0.001$ ). Factor 4 (social activity) was positively correlated with task-oriented $(\mathrm{p}<0.001)$ and avoidance-oriented copings of the CISS $(\mathrm{p}<0.001)$.

Meanwhile, in a correlation analysis with the ACS, factor 1 (personal activity) was positively correlated with problemsolving $(\mathrm{p}<0.001)$ and tension-releasing copings of the ACS $(\mathrm{p}<0.001)$. Factor 2 (pleasure seeking activity) was positively correlated with behavioral aggression $(\mathrm{p}<0.001)$, verbal aggression $(\mathrm{p}<0.001)$ and tension-releasing coping of the ACS $(\mathrm{p}=0.002)$. Factor 3 (compulsive activity) was positively correlated with behavioral aggression $(\mathrm{p}<0.001)$, verbal aggression $(\mathrm{p}<0.001)$ and anger suppression coping of the ACS $(\mathrm{p}<0.001)$. Factor 4 (social activity) was positively correlated with verbal aggression $(\mathrm{p}<0.001)$, problem-solving $(\mathrm{p}<0.001)$ and tensionreleasing copings of the ACS $(\mathrm{p}<0.001)$.

\section{The comparison of behavioral checklist for coping with stress among patients with bipolar or depressive disorders and healthy subjects}

The mean comparison of four factors in the BCCS was compared among patients with bipolar or depressive disorders and healthy subjects (Table 4). The mean value of factor 1 (personal activity) in total patients with bipolar or depressive disorders was significantly lower than in healthy subjects $(\mathrm{p}<0.001)$. The mean value of factor 3 (compulsive activity) in total patients with bipolar disorders was significantly higher than in healthy subjects $(\mathrm{p}<0.001)$. The mean value of factor 4 (social activity) in total patients with bipolar or depressive disorders was significantly lower than in healthy subjects $(\mathrm{p}<0.001)$.

In order to compare the factors of the BCCS between euthymic and depressive state according to bipolar or depressive disorders, the mean values among five groups were compared. The mean values of factor 1 (personal activity) in depressed patients with bipolar or depressive disorders were significantly lower than euthymic patients with bipolar disorder or healthy subjects $(\mathrm{p}<0.001)$. The mean values of factor 3 (compulsive activity) in depressed patients with bipolar disorders was sig-

Table 3. Pearson's correlation between the Behavioral Checklist for Coping with Stress (BCCS) and relevant scales

\begin{tabular}{lcccc}
\hline & $\begin{array}{c}\text { BCCS factor } 1 \\
\text { (personal activity) }\end{array}$ & $\begin{array}{c}\text { BCCS factor } 2 \\
\text { (pleasure-seeking activity) }\end{array}$ & $\begin{array}{c}\text { BCCS factor 3 } \\
\text { (compulsive activity) }\end{array}$ & $\begin{array}{c}\text { BCCS factor } 4 \\
(\text { social activity) }\end{array}$ \\
\hline BDI & $-0.347^{\dagger}(<0.001)$ & $0.017(0.723)$ & $0.345^{\dagger}(<0.001)$ & $-0.300^{\dagger}(<0.001)$ \\
STAI-S & $-0.324^{\dagger}(<0.001)$ & $0.023(0.627)$ & $0.370^{\dagger}(<0.001)$ & $-0.216^{\dagger}(<0.001)$ \\
STAI-T & $-0.296^{\dagger}(<0.001)$ & $0.082(0.078)$ & $0.321^{\dagger}(<0.001)$ & $-0.213^{\dagger}(<0.001)$ \\
BIS & $-0.237^{\dagger}(<0.001)$ & $0.190^{\dagger}(<0.001)$ & $0.347^{\dagger}(<0.001)$ & $-0.068(0.146)$ \\
CISS-task & $0.471^{\dagger}(<0.001)$ & $0.034(0.467)$ & $-0.120^{*}(0.010)$ & $0.322^{\dagger}(<0.001)$ \\
CISS-emotion & $-0.109^{*}(0.020)$ & $0.094^{*}(0.044)$ & $0.457^{\dagger}(<0.001)$ & $0.000(0.999)$ \\
CISS-avoidance & $0.470^{\dagger}(<0.001)$ & $0.157^{\dagger}(0.001)$ & $0.254^{\dagger}(<0.001)$ & $0.565^{\dagger}(<0.001)$ \\
ACS-behavioral aggression & $-0.058(0.215)$ & $0.281^{\dagger}(<0.001)$ & $0.335^{\dagger}(<0.001)$ & $0.003(0.950)$ \\
ACS-verbal aggression & $-0.091(0.052)$ & $0.197^{\dagger}(<0.001)$ & $0.422^{\dagger}(<0.001)$ & $0.159^{\dagger}(0.001)$ \\
ACS-problem solving & $0.400^{\dagger}(<0.001)$ & $0.052(0.268)$ & $-0.029(0.538)$ & $0.349^{\dagger}(<0.001)$ \\
ACS-tension releasing & $0.619^{\dagger}(<0.001)$ & $0.147^{\dagger}(0.002)$. & $0.023(0.623)$ & $0.317^{\dagger}(<0.001)$ \\
ACS-anger suppression & $0.080(0.087)$ & $0.004(0.935)$ & $0.258^{\dagger}(<0.001)$ & $-0.043(0.361)$ \\
\hline
\end{tabular}

Values were shown as Pearson's correlation coefficient ( $\mathrm{p}$ value). ${ }^{*} \mathrm{p}<0.05,{ }^{\dagger} \mathrm{p}<0.01$. NOS: not otherwise specified, BDI: Beck Depression Inventory, STAI-S: State-Trait Anxiety Inventory-state, STAI-T: State-Trait Anxiety Inventory-Trait, BIS: Barratt Impulsivity Scale, CISS: Coping Inventory for Stressful Situation, ACS: Anger Coping Scale 
nificantly higher than euthymic patients with bipolar or depressive disorder or healthy subjects ( $\mathrm{p}<0.001$ ). The depressed patients with depressive disorder also showed higher compulsive activity than euthymic patients with depressive disorders $(\mathrm{p}<0.001)$. The mean value of factor 4 (social activity) in depressed patients with bipolar or depressive disorders was significantly lower than healthy subjects ( $\mathrm{p}<0.001$ ). Additionally, euthymic patients with bipolar disorder significantly showed higher social activity than depressed patients with depressive disorder $(\mathrm{p}<0.001)$.

\section{DISCUSSION}

This study reported the psychometric properties of the Behavioral Checklist for Coping with Stress (BCCS). The factors of the BCCS represented acceptable internal consistency (Chronbach's alpha: 0.695 to 0.833 ). The construct validity of a 39-items behavioral checklist was observed within an acceptable level except several items. Furthermore, this behavioral checklist showed good criterion-related validity with several scales related to psychiatric symptoms and stress-coping. Additionally, the significant differences of the BCCS factors among bipolar or depressive disorder and healthy subjects suggested discriminant validity. Even though the current BCCS showed acceptable reliability and validity, after proper corrections of several items, this behavioral checklist could be a more useful scale to measure stress-coping behaviors.

The results of construct validity by exploratory factor analysis reported that some items had a relatively low factor loading. The factor loading of 'drinking coffee' was 0.310. Based on the results of several studies, caffeinated-beverage consumption was increased in stressful situations. ${ }^{29,30}$ However, the purpose of drinking coffee might be different. Some people may drink coffee in social situations and others tend to use coffee to improve attention power at job demand. ${ }^{29,31}$ In this study, even though 'drinking coffee' was classified into factor 1 (personal activity), the heterogenous reasons to use 'drinking coffee' might lead to a relatively low factor loading. Item of 'sleeping' also showed a low factor loading (0.258) in factor 3 (compulsive activity). Patients with atypical depression can represent hypersomnia as a kind of depressive symptom in stressful situations. ${ }^{32}$ However, some people can also use 'sleeping' in order to get restoration and forget stressful problems for a while. ${ }^{33}$ For this reason, stress-coping behavior of 'sleeping' was not strongly related to factor 3 (compulsive activity). The additional problem in results of construct validity by exploratory factor analysis refers to a high factor loading in more than two factors simultaneously. Items such as 'saying nasty things', 'talking something over' and 'journey' could mean that single behavior intended to seek a different 
purpose, respectively. In case of 'journey', there might be some different meanings between journey alone (factor 1, personal activity) and together (factor 4 , social activity). This item needs to be separate with 'journey alone' or 'journey together' in future studies. Meanwhile, items such as 'saying nasty things' and 'talking something over' had high factor loadings on compulsive and social activities simultaneously. The original purpose of these behaviors might be associated with both resolving inner anxiety and satisfying with social relationship. Given that social supports can alleviate anxiety symptoms, social seeking behavior of using 'talking something over' when feeling anxiety can be predictable. ${ }^{34,35}$ In contrast, social rejection or stressful situation related to social relationship can lead to verbal aggressions or saying nasty things that are not socially advantageous. ${ }^{36,37}$ These items imply that some people tend to choose different stress-coping behaviors according to their own psychological states. If these items are used, the behaviors should be described specifically in order to express the purpose of using each behavior.

Based on the results of criterion-related validity, the factors of the BCCS were meaningfully correlated with each scale of depression, anxiety, impulsivity and coping. Personality or social activities were closely related to adaptive coping such as task-oriented or problem-solving coping. ${ }^{38}$ Individuals with personal activity were less likely to use impulsivity, emotionoriented and avoidance-oriented coping. Different from individuals with personal activity, those with social activity were more likely to use verbal aggressions. As previously explained, people who are seeking social relationship can react aggressively when they are faced with stressful situations related to social relationship. ${ }^{36,37}$ Meanwhile, pleasure-seeking activity was positively correlated with impulsivity, emotion-oriented and avoidance-oriented copings, physical and verbal aggression and tension-releasing anger coping. In other words, pleasure-seeking activity was mostly associated with maladaptive consequences. ${ }^{39,40}$ Compulsivity activity was positively correlated with depression, anxiety, impulsivity, emotion-oriented and avoidance-oriented copings, physical and verbal aggression and anger suppression, and negatively correlated with task-oriented coping. Individuals with compulsive activity showed similar characteristics of those with pleasure-seeking activity. However, they were more likely to feel depressive and anxious symptoms. ${ }^{41,42}$ All factors of the BCCS had a significantly positive correlation with avoidance coping of the CISS. This means that behavioral coping might be a kind of avoidance coping. Even though avoidance coping is known to be a maladaptive coping, some parts of avoidance coping might be adaptive or maladaptive according to the types of stress-coping behaviors. ${ }^{43}$

The results of comparison of the BCCS factors among bi- polar or depressive disorder and healthy subjects showed the differential aspects of stress-coping behaviors according to mood status and diagnostic subtypes of mood disorders. Bipolar or depressive patients tend to use maladaptive behavioral coping strategies, i.e., pleasure-seeking or compulsive activities, not to effectively solve stressful situation compared to healthy subjects. Previous studies suggest that depressed patients with bipolar or depressive disorders were more likely to have maladaptive coping than euthymic patients with mood disorders or healthy subjects. ${ }^{89}$ In addition, individuals at risk of affective disorders may also have maladaptive coping strategies. ${ }^{44}$ These results support the discriminant validity of the BCCS in patients with mood disorders. The evaluation on stress-coping behaviors can predict the mood status and diagnostic subtype of mood disorders.

There are some limitations in this study. Firstly, the sample size in patients with bipolar or depressive disorders was relatively small compared to healthy subjects. Secondly, several items of this checklist have relatively low factor loadings and high factor loadings in more than two factors simultaneously. These items need to be revised to improve the psychometric properties of the BCCS in a future study. Thirdly, BCCS used in this study had not yet been standardized. Thus, BCCS needs to be standardized in larger and representative samples. Also, other tools to confirm its validity such as Received Operating Characteristic Curve analysis as a scale to measure stress-coping strategy should be explored. In addition, since factor structure can be different according to diagnostic subtype of mood disorders, further validation studies in large sample are required.

Nevertheless, this study showed the potentiality of this BCCS as a scale to measure stress-coping behaviors. The evaluation on stress-coping behaviors can predict the symptom status and diagnostic subtype of mood disorders. Additionally, stresscoping behaviors could be an important target to be managed by psychiatrists. The results of this study also suggest the useful information for improving the psychometric properties of the BCCS. Given that the potential role of stress-coping behaviors in stress managements, developing a scale to measure stress-coping behaviors has a clinically crucial implication. In a future study, a modification of this behavioral checklist is expected to facilitate the development of scale to measure stresscoping behaviors.

\section{Acknowledgments}

This study was supported by a grant of Jisan Lee Sejong research fund for cultural psychiatry of Korean Neuropsychiatric Association (2018-172).

\section{Conflicts of Interest}

The authors have no potential conflicts of interest to disclose.

\section{Author Contributions}

Conceptualization: Hyun Ju Lim, Hwagyu Suh, Eunsoo Moon. Data cu- 
ration: Hyun Ju Lim, Sun Kyeong Yang, Hwagyu Suh, Eunsoo Moon, Hee Jeong Jeong, Soo Yeon Kim, Kangyoon Lee. Formal analysis: Hyun Ju Lim, Sun Kyeong Yang, Min Yoon. Investigation: Hyun Ju Lim, Hwagyu Suh, Eunsoo Moon. Methodology: Eunsoo Moon, Je Min Park, Byung Dae Lee, Young Min Lee, Min Yoon. Project administration: Eunsoo Moon. Resources: Eunsoo Moon. Software: Hyun Ju Lim. Supervision: Eunsoo Moon, Je Min Park, Byung Dae Lee, Young Min Lee. Validation: Je Min Park, Byung Dae Lee, Young Min Lee. Visualization: Hyun Ju Lim. Writing_original draft: Hyun Ju Lim, Sun Kyeong Yang, Eunsoo Moon. Writing-review \& editing: Je Min Park, Byung Dae Lee, Young Min Lee, Hee Jeong Jeong, Soo Yeon Kim, Kangyoon Lee, Min Yoon.

\section{ORCID iDs}

$\begin{array}{ll}\text { Hyun Ju Lim } & \text { https://orcid.org/0000-0002-8962-8173 } \\ \text { Eunsoo Moon } & \text { https://orcid.org/0000-0002-8863-3413 } \\ \text { Hwagyu Suh } & \text { https://orcid.org/0000-0002-0360-6708 } \\ \text { Sun Kyeong Yang } & \text { https://orcid.org/0000-0001-8362-1424 } \\ \text { Je Min Park } & \text { https://orcid.org/0000-0003-4700-5856 } \\ \text { Byung Dae Lee } & \text { https://orcid.org/0000-0003-4295-8463 } \\ \text { Young Min Lee } & \text { https://orcid.org/0000-0001-7483-7143 } \\ \text { Hee Jeong Jeong } & \text { https://orcid.org/0000-0003-2833-1648 } \\ \text { Soo Yeon Kim } & \text { https://orcid.org/0000-0002-4056-800X } \\ \text { Kang Yoon Lee } & \text { https:/orcid.org/0000-0001-6748-1097 } \\ \text { Min Yoon } & \text { https://orcid.org/0000-0002-6124-9163 }\end{array}$

\section{REFERENCES}

1. McLaughlin KA, Conron KJ, Koenen KC, Gilman SE. Childhood adversity, adult stressful life events, and risk of past-year psychiatric disorder: a test of the stress sensitization hypothesis in a population-based sample of adults. Psychol Med 2010;40:1647-1658.

2. van Os J, Fahy TA, Bebbington P, Jones P, Wilkins S, Sham P, et al. The influence of life events on the subsequent course of psychotic illness. A prospective follow-up of the Camberwell Collaborative Psychosis Study. Psychol Med 1994;24:503-513.

3. Horesh N, Klomek AB, Apter A. Stressful life events and major depressive disorders. Psychiatry Res 2008;160:192-199.

4. Shapero BG, Black SK, Liu RT, Klugman J, Bender RE, Abramson LY, et al. Stressful life events and depression symptoms: the effect of childhood emotional abuse on stress reactivity. J Clin Psychol 2014;70:209223.

5. Malkoff-Schwartz S, Frank E, Anderson BP, Hlastala SA, Luther JF, Sherrill JT, et al. Social rhythm disruption and stressful life events in the onset of bipolar and unipolar episodes. Psychol Med 2000;30:10051016.

6. Johnson SL, Cueller AK, Ruggero C, Winett-Perlman C, Goodnick P, White $\mathrm{R}$, et al. Life events as predictors of mania and depression in bipolar I disorder. J Abnorm Psychol 2008;117:268-277.

7. Johnson SL, Miller I. Negative life events and time to recovery from episodes of bipolar disorder. J Abnorm Psychol 1997;106:449-457.

8. Orzechowska A, Zajaczkowska M, Talarowska M, Galecki P. Depression and ways of coping with stress: a preliminary study. Med Sci Monit 2013;19:1050-1056.

9. Jung SH, Moon ES, Park JM, Lee BD, Lee YM, Chung YI, et al. Coping Strategies for Stressful Situation in Remitted Bipolar Patients. J Kor Soc Dep Bip Disord 2011;9:177-182.

10. Suh H, Kang TU, Moon E, Park JM, Lee BD, Lee YM, et al. Similarities and differences of strategies between bipolar and depressive disorders on stress coping. Psychiatry Investig 2020;17:71-77.

11. Folkman S, Lazarus RS. Ways of Coping Questionnaire. Palo Alto, CA: Consulting Psychologist Press; 1988.

12. Endler NS, Parker JD. Multidimensional assessment of coping: a critical evaluation. J Pers Soc Psychol 1990;58:844-854.

13. Christensen MV, Kessing LV. Clinical use of coping in affective disorder, a critical review of the literature. Clin Pract Epidemiol Ment Health
2005;1:20.

14. Nitzburg GC, Russo M, Cuesta-Diaz A, Ospina L, Shanahan M, PerezRodriguez M, et al. Coping strategies and real-world functioning in bipolar disorder. J Affect Disord 2016;198:185-188.

15. Reising MM, Bettis AH, Dunbar JP, Watson KH, Gruhn M, Hoskinson $\mathrm{KR}$, et al. Stress, coping, executive function, and brain activation in adolescent offspring of depressed and nondepressed mothers. Child Neuropsychol 2018;24:638-656.

16. Santarnecchi E, Sprugnoli G, Tatti E, Mencarelli L, Neri F, Momi D, et al. Brain functional connectivity correlates of coping styles. Cogn Affect Behav Neurosci 2018;18:495-508.

17. van den Heuvel MWH, Stikkelbroek YAJ, Bodden DHM, van Baar AL. Coping with stressful life events: Cognitive emotion regulation profiles and depressive symptoms in adolescents. Dev Psychopathol 2020;32: 985-995.

18. Moon E, Chang JS, Choi S, Ha TH, Cha B, Cho HS, et al. Characteristics of stress-coping behaviors in patients with bipolar disorders. Psychiatry Res 2014;218:69-74.

19. Choi Y, Moon E, Park JM, Lee BD, Lee YM, Jeong HJ, et al. Psychometric properties of the coping inventory for stressful situations in Korean adults. Psychiatry Investig 2017;14:427-433.

20. Beck AT, Steer RA. Internal consistencies of the original and revised Beck Depression Inventory. J Clin Psychol 1984;40:1365-1367.

21. Lee MK, Lee YH, Park SH, Sohn CH, Jung YJ, Hong SK. A standardization study of beck depression inventory(I): Korean version(K-BDI): reliability and factor analysis. Korean J Psychopathol 1995;4:77-95.

22. Spielberger CD, Gorsuch RL, Lushene RE. Manual for the State-Trait Anxiety Inventory. Palo Alto, CA: Consulting Psychologist Press; 1970.

23. Kim JT, Shin DK. A study based on the Standardization of the STAI for Korea. New Med J 1978;21:69-75.

24. Barratt ES. Factor analysis of some psychometric measures of impulsiveness and anxiety. Psychol Rep 1965;16:547-554

25. Lee HS. Impulsiveness Test Guide. Seoul; Korean Guidance; 1992.

26. Endler NS, Parker JD, Butcher JN. A factor analytic study of coping styles and the MMPI-2 content scales. J Clin Psychol 1993;49:523-527.

27. Park YC, Kim KI, Noh S. Validity assessment of the CISS (Coping Inventory for Stressful Situation) in Korean high school students. J Korean Neuropsychiatr Assoc 2000;39:55-64.

28. Koh KB, Park JK. Development of the anger coping scale. J Korean Neuropsychiatr Assoc 2005;44:477-488.

29. Steptoe A, Wardle J. Mood and drinking: a naturalistic diary study of alcohol, coffee and tea. Psychopharmacology (Berl) 1999;141:315-321.

30. Concerto C, Conti C, Muscatello MR, Signorelli MS, Zoccali R, Coira $\mathrm{D}$, et al. Sleep quality, perceived stress, and caffeinated drinks intake in psychiatry residents: a cross-sectional study. J Caffeine Res 2017;7:1822.

31. Holle C, Heimberg RG, Sweet RA, Holt CS. Alcohol and caffeine use by social phobics: an initial inquiry into drinking patterns and behavior. Behav Res Ther 1995;33:561-566.

32. Keller MC, Neale MC, Kendler KS. Association of different adverse life events with distinct patterns of depressive symptoms. Am J Psychiatry 2007;164:1521-1529; quiz 1622.

33. Vandekerckhove M, Cluydts R. The emotional brain and sleep: an intimate relationship. Sleep Med Rev 2010;14:219-226.

34. Barnett MD, Maciel IV, Johnson DM, Ciepluch I. Social anxiety and perceived social support: gender differences and the mediating role of communication styles. Psychol Rep 2021;124:70-87.

35. Hyde LW, Gorka A, Manuck SB, Hariri AR. Perceived social support moderates the link between threat-related amygdala reactivity and trait anxiety. Neuropsychologia 2011;49:651-656.

36. Wright MF, Li Y. The association between cyber victimization and subsequent cyber aggression: the moderating effect of peer rejection. J Youth Adolesc 2013;42:662-674.

37. Kalvin CB, Bierman KL, Gatzke-Kopp LM. Emotional reactivity, behavior problems, and social adjustment at school entry in a high-risk sam- 
ple. J Abnorm Child Psychol 2016;44:1527-1541.

38. Smith MM, Saklofske DH, Keefer KV, Tremblay PF. Coping strategies and psychological outcomes: the moderating effects of personal resiliency. J Psychol 2016;150:318-332.

39. Adams ZW, Kaiser AJ, Lynam DR, Charnigo RJ, Milich R. Drinking motives as mediators of the impulsivity-substance use relation: pathways for negative urgency, lack of premeditation, and sensation seeking. Addict Behav 2012;37:848-855.

40. Romer D, Betancourt LM, Brodsky NL, Giannetta JM, Yang W, Hurt H. Does adolescent risk taking imply weak executive function? A prospective study of relations between working memory performance, impulsivity, and risk taking in early adolescence. Dev Sci 2011;14:1119-1133.
41. Garcia GD, Pompeo DA, Eid LP, Cesarino CB, Pinto MH, Goncalves LWP. Relationship between anxiety, depressive symptoms and compulsive overeating disorder in patients with cardiovascular diseases. Rev Lat Am Enfermagem 2018;26:e3040.

42. Kramer U, Zimmermann G. Fear and anxiety at the basis of adolescent externalizing and internalizing behaviors: a case study. Int J Offender Ther Comp Criminol 2009;53:113-120.

43. Beutler LE, Moos RH, Lane G. Coping, treatment planning, and treatment outcome: discussion. J Clin Psychol 2003;59:1151-1167.

44. Vinberg M, Froekjaer VG, Kessing LV. Coping styles in healthy individuals at risk of affective disorder. J Nerv Ment Dis 2010;198:39-44. 